\title{
Transatlantica
}

Revue d'études américaines. American Studies Journal

\section{Christiane Desafy-Grignard. Arthur Miller.}

Paris : Belin, 2001.128p.

\section{Susan Blattès}

\section{(2) OpenEdition}

Journals

Édition électronique

URL : http://journals.openedition.org/transatlantica/731

DOI : 10.4000/transatlantica.731

ISSN : $1765-2766$

Éditeur

AFEA

\section{Référence électronique}

Susan Blattès, "Christiane Desafy-Grignard. Arthur Miller. », Transatlantica [En ligne], 1 | 2003, mis en ligne le 05 avril 2006, consulté le 29 avril 2021. URL : http://journals.openedition.org/transatlantica/ 731 ; DOI : https://doi.org/10.4000/transatlantica.731

Ce document a été généré automatiquement le 29 avril 2021

\section{(c) (†) $\ominus$}

Transatlantica - Revue d'études américaines est mis à disposition selon les termes de la licence Creative Commons Attribution - Pas d'Utilisation Commerciale - Pas de Modification 4.0 International. 


\section{Christiane Desafy-Grignard. Arthur Miller.}

Paris : Belin, 2001.128p.

\section{Susan Blattès}

1 Raconter la vie et l'œuvre d'Arthur Miller en moins de 130 pages n'est pas facile, surtout si, comme le fait Christiane Desafy-Grignard, l'objectif est de faire connaître aux jeunes générations non seulement l'homme de théâtre, mais aussi le romancier, l'essayiste et l'intellectuel qu'est cet Américain de 87 ans. En effet, Miller a beaucoup écrit et continue à écrire depuis ses premières pièces qui datent des années 30 . La bibliographie proposée est nécessairement limitée. Etant donné qu'il est plus facile en France d'avoir accès aux éditions britanniques qu'aux éditions américaines, il aurait été utile de signaler que Methuen publie des recueils des pièces de Miller. Le volume 5 a été publié en 1995 et contient The Last Yankee et The Ride Down Mount Morgan. Quant à la bibliographie critique, que l'auteur a été obligée de réduire considérablement, on peut y ajouter l'ouvrage de C.W.E. Bigsby (The Cambridge Companion to Arthur Miller, Cambridge : Cambridge UP, 1997) qui a l'avantage de consacrer un chapitre à chacune des pièces les plus importantes.

Le livre de Christiane Desafy-Grignard n'est pas organisé chronologiquement, mais thématiquement, autour de quelques notions fondamentales dans l'œuvre de Miller. Elle aborde notamment la crise de 1929 (chapitre 3), le Rêve américain (chapitre 4) et la question de l'authenticité (chapitre 6), autant d'idées centrales chez Miller. Christiane Desafy-Grignard souligne notamment l'attitude très ambivalente de Miller, «un Américain qui dérange ", envers le Rêve américain. Cette organisation permet d'aborder les œuvres les plus significatives. Très judicieusement, l'auteur nous renvoie régulièrement à l'autobiographie de Miller (Timebends: A Life), ouvrage indispensable à celui qui s'intéresse à cet écrivain. La décision de comparer pièces et nouvelles apporte aussi une certaine originalité à cette étude, puisque les nouvelles sont bien moins connues. 
Evidemment, dans un ouvrage si court, il est impossible d'étudier en détail les subtilités de l'écriture théâtrale de Miller, qui reste avant tout homme de théâtre. Ainsi, l'auteur doit parfois analyser très rapidement les procédés théâtraux employés. Il faudrait consacrer plus d'un paragraphe aux techniques utilisées, par exemple, dans The American Clock

(75).

Dans le chapitre 7 ( Un dramaturge de l'air du temps »), Christiane Desafy-Grignard lie les écrits de Miller à des événements précis de l'histoire américaine, même si Miller luimême semble vouloir éviter de trop s'appuyer sur l'actualité. Cette méthode entraîne une certaine répétition puisqu'elle oblige l'auteur à revenir sur l'importance de la crise de 1929, par exemple, événement qui revient sans cesse dans l'œuvre de Miller. Si une pièce comme The Crucible semble très liée à son époque, ce n'est pas le cas de bien d'autres pièces. Il est clair que les pièces de Miller, même si elles reflètent le climat psychologique, économique et social de l'Amérique à certains moments, dépassent ce cadre. C'est pour cela que les pièces les plus célèbres ont été reprises de nombreuses fois un peu partout dans le monde au cours des cinquante dernières années.

Christiane Desafy-Grignard a certainement raison, dans sa conclusion, d'insister sur le fait que Miller est "plus humaniste que politique » (115). On peut regretter qu'elle ne puisse nous montrer en quoi les pièces sont dignes d'intérêt, les grandes œuvres mériteraient chacune une étude spécifique, mais au moins elle nous incite à découvrir ou à redécouvrir l'un des plus grands écrivains dramatiques contemporains.

INDEX

Thèmes : Recensions

\section{AUTEUR}

SUSAN BLATTÈS

Université Stendahl - Grenoble 3 